\title{
EL NEGOCIO DE LA POLÍTICA: NACIÓN, CIUDADANÍA Y RAZA EN EL CARIBE COLOMBIANO, 1810-1830
}

\author{
Jorge Conde Calderón*
}

\section{INTRODUCCIÓN}

Desde hace dos siglos los gobiernos republicanos se han hecho presentes en el mundo iberoamericano constituyéndose en estados naciones cuya soberanía reside en el pueblo. Una vez iniciado el proceso de independencia, en 1810, aparecieron de manera simultánea los problemas inherentes a la construcción de esos estados naciones. El principal se refería a la ciudadanía política y al régimen representativo. Las élites criollas necesitaban definir la condición de los habitantes que como portadores de derechos legitimaran el nuevo orden. Es decir, aquellos en capacidad de sufragar y de elegir. De esta manera se realizó la invención del ciudadano y el concepto pueblo como ente soberano pasó a ser básico en el lenguaje de la época, aunque su definición tuviera diversas acepciones.

Por consiguiente, al problema de la representación se articularon los de la definición del concepto pueblo. Quiénes debían ser los representantes y quiénes serían los representados. Este asunto, sin embargo, resultó solucionándose a través de la influencia de la tradición política hispánica y el peso de lo racial acompañados, en algunas regiones, por una negociación política cuyos protagonistas utilizaron la coacción, sutil o violenta durante el proceso.

Dada la composición racial del Caribe colombiano con un elevado porcentaje de mestizos, con una fuerte presencia de mulatos, pardos y zambos, las

\footnotetext{
* Profesor de Historia, Universidad del Atlántico, jconde@ metrotel .net.co
} 
denominadas castas ${ }^{1}$, que en su gran mayoría, en los centros urbanos portuarios, ejercían oficios de estibadores, milicianos, artesanos y algunos con pequeños negocios, se constituyeron un factor clave en la definición de la representación ciudadana. Para lograr el derecho de ciudadanía se recurrió a la movilización política de esa clase social ${ }^{2}$, de la que las oligarquías locales y nacionales querían, al mismo tiempo, tomar distancia. Sin embargo, el significativo peso social y demográfico de mulatos, pardos y zambos canalizó la movilización hacia la negociación y manipulación política de lo racial, tanto de parte de estos mismos grupos raciales como de las élites. En estas últimas, ambas acciones siempre estaban acompañadas del temor de una revolución social de las castas o una guerra de razas.

Estas circunstancias, ocurridas entre los años 1810 y 1830, serán reseñadas en el presente trabajo. Durante este período se estaban discutiendo las distintas formas de construcción y consolidación de la nación, pero también se configuraban las distintas agrupaciones o facciones partidistas. En el caso de los mulatos, pardos y zambos su forma de representarse la nación y considerarse ciudadanos fue la de una lucha social por incorporarse como hombres de honor y estatus en la sociedad que les rodeaba, es decir en la nación que esperaban como resultado de la guerra de emancipación. Para ellos fue también una lucha para adquirir medios para poder ganarse la vida o, dicho de otra manera, una política que les permitiera adquirir un empleo o una profesión.

\section{NACIONES IMAGINADAS, REPRESENTACIONES POLÍTICAS}

Unos meses después de la instalación de la Suprema Junta de Gobierno en Cartagena de Indias, José Fernández de Madrid y Castro, uno de los directores

\footnotetext{
${ }^{1}$ El peso de las castas, que en las provincias del Caribe colombiano iban acompañadas de la denominación "libres de todos los colores", era de tal proporción que uno de los ideólogos de la República de Colombia comentando la ley que, en 1821, extinguía los tributos indígenas y los igualaba con los demás ciudadanos celebraba que "En lo venidero los indígenas comenzarán a mezclarse con las demás castas, se mejorarán, se cultivarán sus tierras y saldrán de la abyección y abatimiento en que los había sumido el pupilaje perpetuo a que los sujetaban las leyes españolas", véase, RESTREPO, José Manuel, Diario político y militar, Bogotá, Imprenta Nacional, 1954, Tomo I, p. 144.

2 En los escritos contemporáneos cuando se referían a clase social la pertenencia de un individuo, a alguna de las existentes, lo definía su posición en la escala racial. Por esa razón utilizamos el concepto raza en el presente trabajo.
} 
del periódico Argos, papel impreso que hacía las veces de portavoz político de esa corporación, discurría sobre el modelo adecuado para gobernar el territorio de la Nueva Granada. Según José Fernández no era el caso imitar ciegamente el sistema de gobierno de los ingleses y norteamericanos, digno, por demás, de admirar dada su sabiduría. Sin embargo, como no pretendía pasar por original, ni le movía otra intención que el de contribuir de su parte a la felicidad de la patria, algunas veces incurría en proponerlos como los mejores modelos aunque aclarando que debido a "nuestras costumbres, situación, diferencia de clases, y otras mil circunstancias nos prohíben dirigirnos por sus mismos principios. Por tanto, es necesario desprendernos de todo espíritu de partido y prevención para combatir con imparcialidad ciertos sistemas erróneos que canonizados por el voto común han adquirido el aspecto de verdades indudables" ${ }^{3}$.

La importancia de las reflexiones de Fernández de Madrid radica en que éstas lo conducían a plantear el problema de la nación, la ciudadanía política y el régimen representativo reconociendo la existencia de una marcada diferencia de clases, que en el espacio caribeño neogranadino era entendida como diferencia de razas. Este elemento sería decisivo al momento de definir el tipo de nación y representación que se quería. Si bien el modelo de nación planteada por alguna de las clases existentes pertenecía a la esfera de su imaginación, la definición del tipo de representación debía tener en cuenta, e incluir aunque sólo fuera como sufragantes, a clases hasta el momento excluidas del sistema sociopolítico por el color de la piel, es decir, las castas o la "popularidad tumultuaria", para utilizar una expresión de la época.

Definidas esas cuestiones sociales básicas, desde las páginas de Argos fue propuesto un tipo de representación con el cual la calidad de iguales se hizo extensiva a todos los vecinos del lugar. Se soslayaba aún el asunto de la ciudadanía política, tema de posterior definición en la Constitución del Estado de Cartagena de Indias, en 1812. Todavía, durante el primer año, se consideró que debía realizarse el establecimiento de un gobierno patriótico y de entera confianza de los miembros de la corporación cartagenera conforme a los principios y el modelo que a todos los pueblos americanos había propuesto la

3 "Continúan las reflexiones sobre nuestro estado", en: El Argos Americano, Papel político, económico y literario de Cartagena de Indias, 22 de octubre de $1810, \mathrm{~N}^{\circ} 6$. 
Junta de Gobierno de Cádiz, pues lo contrario significaba atentar contra la unión con la Metrópoli. Lo inexplicable de esa consideración era que, a mediano plazo, esto conducía directamente a un choque con los argumentos sobre el tipo de representación elegido por la élite cartagenera.

Sobre esa cuestión el editor del periódico citado sostuvo el punto de vista de una influencia decisiva en el desarrollo de los posteriores acontecimientos políticos que derivaron hacia posiciones radicales, en la lucha política entre las diferentes clases, relacionadas con los cambios específicos acaecidos en la distribución del poder dentro del Estado Libre y Soberano de Cartagena de Indias. En su momento Fernández de Madrid escribió: "en todo gobierno la Nación es representada por aquel o aquellos individuos a quienes confía una parte de su libertad para conservar el resto, porque el hombre no se despoja de esta porción preciosa de sus derechos sino por el interés de vivir tranquilo, defendido por las armas de los ataques exteriores y por las leyes de la violencia con que pudiera oprimirle otro hombre más fuerte y poderoso. De aquí infiero que todo vecino útil tiene facultad de nombrar sus representantes, que privarlos de ella es injusticia y despotismo, es violar en una palabra los más sagrados principios del derecho público: infiero también que el ciudadano honrado que por las vicisitudes del tiempo, o por un efecto del desgobierno en que hemos vivido se hallase en la pobreza no por eso perderá el derecho de votar a favor de aquellos a quienes conceptúe idóneos para mejorar la desgraciada suerte; y últimamente infiero que caeríamos en los dichos escollos si tratásemos de seguir en esta parte el sistema que observan la Gran Bretaña y los Estados Unidos"4.

Al reconocer tanto a todo vecino útil como al ciudadano honrado, aunque pobre, la facultad de nombrar sus representantes, ese tipo de representación política aceptaba la estratificación social y diferencia racial profundamente arraigadas de la sociedad cartagenera, pero atenuaba cualquier peligro de una guerra de razas aceptando a sus miembros como iguales ante la legislación estatal y desiguales sólo social y económicamente.

\footnotetext{
4 “Continúan las reflexiones sobre nuestro estado", en: El Argos Americano, 12 de noviembre de 1810, N 9. Cursivas nuestras.
} 
Sin desconocer la desventaja que la igualdad ante las leyes significaba para el patriciado urbano cartagenero, el autor citado anticipaba la necesidad, en un futuro, de limitar la facultad de sufragar. Por esa razón a renglón seguido establecía que "si los americanos quieren dar al mundo un testimonio de rectitud y justificación deberán determinar, que hasta el año de 1816, todo vecino de conocida honradez por miserable y pobre que sea, puede elegir sus representantes y ser él mismo elegible: pero que dicho año en adelante se haga un censo general del estado de los bienes de cada ciudadano y que no se concedan las expresadas facultades sino a los que posean al menos 2 [mil] pesos en bienes muebles o raíces [...]. De este modo conseguirá la Patria la doble ventaja de estimular a sus hijos al trabajo, y se evitarán los inconvenientes de que hemos hablado en los números anteriores [...]. Así como es muy justo que todo ciudadano por infeliz que sea disfrute del derecho de sufragio, lo es igualmente que carezcan de tan preciosa facultad aquellos individuos corrompidos que lejos de servir a la sociedad la perjudican, y prostituyen. Bajo esta denominación se comprenden los que han sufrido pena infamatoria, o corporis aflictiva o los que tienen causa criminal pendiente. Deberán igualmente proscribirse los holgazanes, o zánganos de la república que la agotan y consumen en vez de fomentarla, tales son los vagos públicos. Tampoco obtendrán dicha facultad los que por su estado y circunstancias no pueden contribuir por su parte al bienestar común, en cuya clase están incluidos los que adeudan a la Real Hacienda, lo fallidos, los insensatos, los sordomudos, los transeúntes o extranjeros, a no ser que estén avecindados"5.

Al final, siguiendo lo aprobado por los constituyentes españoles de 1812, la élite cartagenera reconoció de hecho un sufragio casi universal que identificaba al pueblo político con la mayor parte de la población masculina; es decir, a los varones vecinos del lugar Sm embargo, a diferencia de la constitución liberal gaditana que discriminaba a las castas, con gran perjuicio para los mulatos de piel clara, los constituyentes cartageneros, por constituir esta clase social un elemento político influyente en el gobierno de la ciudad y en eventuales elecciones, extendieron la igualdad legal a todos los vecinos libres sin distinción del color de la piel.

\footnotetext{
${ }^{5}$ Ibíd.
} 
Al mismo tiempo, en nombre de la independencia social y de la interpretación de la noción ciudadano, fueron excluidos los menores de edad, los servidores y, sin señalarlo expresamente, se mantuvo la distinción entre nobles y plebeyos, en lo relativo a la aplicación de penas y castigos ${ }^{6}$.

Las conclusiones de ese gran debate sobre la representación y ciudadanía política fue recogido en la Constitución del Estado de Cartagena de Indias del año 1812. Esta carta estaba dirigida "A todos los habitantes de él, de cualquier clase y condición que sean", pues, "El cuerpo político se forma por la voluntaria asociación de los individuos; es un pacto social en que la totalidad del pueblo estipula con cada ciudadano, y cada ciudadano con la totalidad del pueblo, que todo será gobernado por ciertas leyes para el bien común. Por tanto, es el deber de un pueblo reunido para constituir su gobierno, proveerle del modo más justo y equitativo de hacer leyes, de su interpretación imparcial, fiel y exacta ejecución, para que todo ciudadano en cualquier tiempo encuentre en ellas su apoyo y seguridad"7. También señalaba que los empleos públicos se proveen a los ciudadanos por cualidades admisibles como el de servir a la patria, vigencia de su capacidad legal para elegir y ser elegido, y "durante el buen desempeño"8.

Lo recogido en la Constitución del Estado de Cartagena no sólo era consagrado por ella. Otras constituciones expedidas a partir de 1810, en la Nueva Granada, también extendieron un manto de igualdad sobre quienes eran considerados "el pueblo". Por ejemplo, la Constitución de la República de Cundinamarca, en 1812, en el artículo 4, señalaba: "El pueblo es la universalidad de los ciudadanos, y ninguna parcialidad de gentes puede arrogarse el nombre de pueblo".

\footnotetext{
6 "Reglamento formado de orden de la Suprema Junta para substanciar y determinar breve y sumariamente las causas que ocurran sobre robos, uso de armas prohibidas, y quimeras", El Argos Americano, 17 de diciembre de $1810, \mathrm{~N}^{\circ}$ 12. Para una comparación con el sistema electoral elaborado por los constituyentes españoles de 1812, véase la "Constitución de Cádiz (1812)", en: El pensamiento constitucional hispanoamericano hasta 1830. Caracas, Biblioteca de la Academia Nacional de la Historia, 1961, pp. 287-395. Los nobles también reconocidos como los aristócratas, eran la clase social dominante definidos por ser de piel blanca y poseer un patrimonio mobiliario y cultural, preferiblemente, urbano. La conjunción de todos esos elementos los hacía ser los individuos notables para ejercer cargos públicos.

7 “Constitución Política del Estado de Cartagena de Indias expedida el 14 de Junio de 1812", En: Ibid, p. 76.
}

8 Ibíd, p. 79. 
En el artículo siguiente establecía: "En virtud de la igualdad, todos los ciudadanos tienen derecho para obtener los empleos públicos, y entre ellos no se debe conocer otra preferencia que la que le dan el talento, las virtudes y el mérito"9.

Ahora bien, la diferencia entre las dos constituciones se establece a partir de a quienes se consideró integrantes del pueblo. Mientras la cartagenera tendió un manto de igualdad sobre todas las clases, lo que incluía a los "libres de todos los colores", es decir, las castas; la de Cundinamarca, por la mayoritaria presencia indígena en su espacio provincial, extendió los derechos de ciudadanos a todos los indios con "voz y voto en todas las elecciones, como los demás de esta república" ${ }^{\prime 10}$.

Con visión hemisférica la Constitución de la República de Colombia, en 1821, no utiliza el concepto ciudadanos sino el más amplio y específico de colombianos, que son todos los hombres libres nacidos en el territorio de la nación colombiana, en la que reside la soberanía. Pero también admitía como colombianos a los que estaban radicados en Colombia al tiempo de la transformación, con tal que permanecieran fieles a la Independencia y a los no nacidos en ella que obtuvieran carta de naturaleza ${ }^{11}$.

Por consiguiente a través de las sucesivas legislaciones la igualdad ciudadana fue extendida a un conjunto amplio de la población, que comenzó a utilizarla como herramienta política. Esa estrategia de reacomodo político fue evidente en nuevos grupos sociales como el de los abogados, letrados, militares o milicianos, que con la guerra de emancipación y el establecimiento del gobierno republicano encontraron la manera de llevar a cabo su promoción y movilidad social.

9 “Constitución de la República de Cundinamarca (1812)", En: El pensamiento constitucional hispanoamericano hasta 1830. Caracas, Biblioteca de la Academia Nacional de la Historia, 1961. Tomo IV, p. 12.

${ }^{10}$ Ibíd,p. 14.

11 "Constitución de la República de Colombia, Año de 1821 -11² Rosario de Cúcuta”, En: Manuel Antonio Pombo y José Joaquín Guerra, Constituciones de Colombia. Bogotá, Octubre 12 de 1892, p. 119. 
La prosperidad de esa situación provocaba recelos, temores infundados o reales, y vanas esperanzas como las del creador del mito fundacional de la nación colombiana de blancos, que ante el ascenso de esos nuevos grupos sociales sólo esperaba una fuerte inmigración extranjera para evitar el riesgo de una guerra civil intestina con los negros y mulatos la que, en su concepto, haría perder la república ${ }^{12}$.

\section{BOCHINCHES DE COLORES}

En el año 1825 Ignacio Muñoz, abogado de la república, encargado de la defensa de los pobres y menores de la ciudad de Cartagena, describía al encargado del supremo poder ejecutivo, General Francisco de Paula Santander, las circunstancias de su enfrentamiento con el General José Prudencio Padilla y terminaba su misiva señalando que éste era "un cobarde semejante, indigno de llevar charreteras en ninguna nación"13.

Este conflicto era uno más de los muchos que se sucedían, en la incipiente nación colombiana, como producto de los enfrentamientos personales entre los diferentes actores políticos y sociales agrupados en facciones enemigas. Estas eran a su vez movilizadas por diversos caudillos locales o definidas por adscripciones clientelares a la oligarquía en un espacio provincial alejado del poder central, sin apenas organización militar, pero apoyados por la fuerza de las masas, la mayoría de las veces manipuladas o utilizadas ${ }^{14}$.

Debido al contexto político de la época, el lenguaje empleado y las características sociales de los actores en los conflictos, estos hechos condensaban varios problemas que afectaban al proyecto de nación concebido por las oligarquías nacionales y locales. El primer problema era el referente a

12 RESTREPO, José Manuel, Op. Cit, p. 222.

13 "Ignacio Muñoz al excmo. señor encargado del supremo poder ejecutivo, Cartagena a 30 de mayo de 1825" en: CORTAZAR, Roberto, comp. Correspondencia dirigida al General Santander, Bogotá, Tomo VIII, 1966, N 2.922, pp. 468-470.

14 MARCHENA FERNANDEZ, Juan, "Militarismo y constitucionalismo en el ocaso del orden colonial en la Sierra Andina”, En: Chris Wickham, Henry Kamen, Elena Hernández Sandoica y otros, Las crisis en la Historia, Ediciones Universidad de Salamanca, 1995, pp. 101-118. 
la recomposición de los poderes locales, que tenían en las ciudades los espacios propicios de su acción y confrontación política. En el contexto de la tradición hispánica las ciudades habían sido los ámbitos donde la oligarquía urbana ejerció el poder, principalmente a través del control político del cabildo. Este cuerpo consultivo fue la base jurídica del núcleo expansivo hispanoamericano, por ser el símbolo institucional representativo de la existencia de la ciudad, elemento clave en la primera república entre 1810 y 1815. Sin embargo, con el advenimiento del sistema de gobierno republicano el espacio político urbano colonial con base en el cabildo fue sucedido por la conformación del nuevo espacio político estatal provincial, a cuya consolidación contribuyó la instauración del nuevo régimen representativo en 1821 con la consiguiente ampliación de la frontera política.

Esta novedosa recomposición del poder seguía en ejercicio del mismo por medio de los cargos y podía aumentar considerablemente si éstos se acumulaban y monopolizaban, pues, diversas funciones en una misma persona conducían a ingeniosos juegos de poder y de luchas, con el propósito de ganar mayor influencia y manejar las situaciones con más soltura y libertad. Con el advenimiento de la República hubo cambios significativos en los individuos que ejercieron el poder, en lo concerniente a su composición social y política. Éstos fueron llamados los "notables" y estaban definidos por categorías como el linaje, la raza, la pertenencia a la clase social de los nobles o aristócratas, y poseer patrimonio económico.

La escogencia de los notables para el desempeño de los cargos públicos colisionaba con los nuevos grupos sociales, que habían logrado su promoción y ascenso social y político reclamando su servicio a la patria, ser hombre de honor y patriota, haber participado en la guerra emancipadora, etc. Medios de comunicación y forjadores de opinión pública como la prensa, los pasquines, libelos y hojas sueltas, eran los espacios propicios donde se confrontaban ideas sobre el tipo de representación ciudadana y el futuro de la nación, pero también los que reproducían programas de algún candidato en determinada coyuntura electoral, rechazaban abiertamente las propuestas del candidato distinto al de sus preferencias o le recordaban asuntos de su pasado reciente con relación a la patria, la nación y hasta su intimidad. Esta confrontación adquiría una 
connotación virulenta cuando se aproximaba el día de las elecciones, entonces podían aparecer hasta los ataques personales.

En apariencia, el nuevo régimen político borró las diferenciaciones jerárquicas del antiguo régimen español basadas en lo racial y en la pertenencia a una localidad, ya fuera ciudad o villa. La nueva estratificación social comenzó a definirse por los patrones de riqueza, pero el orden constitucional introdujo la categoría de "ciudadanos", hecho que permitió la puesta en escena de grupos sociales (abogados, letrados, militares o milicianos), tradicionalmente sometidos a los patrones de conducta de los sectores dominantes.

Ese conflicto entre Ignacio Muñoz y José Prudencio Padilla es significativo por tratarse de dos actores de primer orden en la vida política provincial caribeña y por llevar sobre sí la impronta de ser mulatos o de estar próximos a ellos, aunque lo racial, en el nuevo orden republicano, aparentemente había perdido importancia alguna. Ambos afirmaban sus valores y dignidades como hombres de la patria desde sus participaciones en los acontecimientos de la primera república independiente. En el conflicto se mezclaban varias situaciones. Ambos, comprometidos sentimentalmente con las hijas del artesano Pedro Romero, un pardo natural de Cuba, que en 1810 era Comandante del Cuerpo de Patriotas "Lanceros de Getsemaní" y dirigió la movilización política, entre 1810yl815, de los sectores plebeyos cartageneros. Sus hijas Ana María de la Concepción y María Josefa Teodora, también naturales de la isla antillana, eran dos atractivas mulatas. La primera estuvo casada con el patriota cartagenero Teniente Coronel Ignacio José de Marte y de la Torre, de quien se separó para hacer vida marital con el Almirante Padilla; la segunda estaba casada con Ignacio Muñoz (conocido como el Tuerto Muñoz), natural de Corozal, en la Provincia de Cartagena ${ }^{15}$.

El conflicto de Muñoz con Padilla se remitía a la delicada acusación que el primero le hacía al segundo con referencia a que su mujer lo había abandonado por su culpa. Padilla le escribiría a Santander una extensa carta relatándole todos los detalles de las injurias, ofensas y agresiones personales que tuvieron

${ }^{15}$ RESTREPO LINCE, Pastor, Genealogías de Cartagena de Indias, Instituto Colombiano de Cultura, 1993, pp. 477-478. Los otros hijos de Pedro Romero eran: María Francisca, María de la Caridad, también naturales de Cuba, Pedro, Mauricio José, Manuel Antonio, Tomás, Sebastián y Joaquín, todos nacidos en Cartagena. 
lugar con Muñoz, debidas a que éste estaba "creído de que mi sufrimiento venía de otro principio (de su mujer)" ${ }^{\prime 16}$.

Independientemente de este hecho, lo real era que Padilla contaba con ascendencia entre los sectores plebeyos. Su oficio de marino le permitía moverse por el espacio caribeño, en su parte litoral, desde Maracaibo hasta más allá de Cartagena y hacia el interior llegaba hasta Mompós. Esa movilidad le facilitaba el contacto permanente con esos sectores y despertaba los celos de sus rivales políticos. Manifestaciones de ese tipo eran evidentes en Mariano Montilla, Comandante General del Departamento del Magdalena ${ }^{17}$, que le informaba al "Vicepresidente Santander (reservadísimo y para usted sólo, porque estoy escamado) sobre el inconsulto e inesperado arribo del hábil marinero a Cartagena, "donde vuelven los bochinches de colores, Padilla que se empeñó en ir allí a ver la moza por ocho días, decretó en la Popa muerte a los nobles, etc., por no sé qué desaire que quisieron hacer a su moza que es una pardita hermana de Romero ${ }^{18}$ y que vive con él públicamente. El doctor Real [ejercía el cargo de Intendente] está casado con una mulatica de la pandilla, y usted debe abrir bien los ojos sobre aquella ciudad. Como no ha llegado Pérez, aún no sé el motivo de su embajada, que no será otro que las amenazas de la gente de color. Ucrós, casado con una pardita; Montes, su cuñado; Núñez, alcalde muy impregnado de los Cayos, donde ha vivido largos años, y la mitad del cabildo de la misma clase, debe hacer observar de cerca el país"19.

En cartas similares el General venezolano insistía a Santander en el peligro "de los bochinches de Cartagena que se reducen a especies y dichos de los de color

16 "General José Prudencio Padilla al Excmo. Vicepresidente de la República F. de P. Santander, Cartagena 10 de mayo de 1825", citado en, Jesús C. Torres Almeyda, El Almirante José Padilla (Epopeya y martirio), Bogotá, Ediciones El Tiempo, 1983, p. 127.

17 La nueva división territorial de la República de Colombia dispuso para el Caribe neogranadino como unidad político-administrativa superior el Departamento de Magdalena, gobernado por un Intendente e integrado por las provincias de Cartagena, Santa Marta, Riohacha y Mompós.

18 La referencia era a Mauricio José Romero Domínguez. Abogado. Miembro de la Comisión Permanente de Guerra de la plaza de Cartagena sitiada en 1815 en unión de los patriotas, Ignacio Cavero y Basilio del Toro de Mendoza. Representante por Cartagena en el Congreso Nacional de la Nueva Granada en Bogotá y su Vicepresidente en 1832, como tal firmó la Constitución de la Nueva Granada. Secretario de la Gobernación de Cartagena en 1835, fue Tesorero en 1837, véase, RESTREPO LINCE, Pastor, Op. Cit.,p. 478.

19 Mariano Montilla al Excmo. Sr. General F. de P. Santander, etc. Santa Marta, febrero 20de 1823”, en: CORTÁZAR, Roberto, Op Cit., N-2.743, p. 179. Cursivas nuestras. 
animados por el pasaje de Padilla que fue tan público como escandaloso en la Popa, ofreciendo hacer la guerra a los blancos y a los nobles". Sin embargo, dejaba traslucir algún alivio por la salida de Padilla para Riohacha, aunque reaccionaba de inmediato por el arribo a la ciudad de Cartagena de un nuevo emigrado, que había salido de la Nueva Granada durante la guerra de emancipación, de Jamaica, los Cayos o Haiti ${ }^{20}$.

Exactamente un año antes Montilla había sugerido a Santander "tomar algunas medidas prohibitivas y prudenciales", para evitar el arribo de emigrados, pues no era "conveniente la admisión de la gente de los Cayos, etc., en esta costa". Además le informaba cómo él estaba aplicando medidas de ese estilo, las que tenía "comunicadas reservadamente a los gobernadores", observando mucho a los recién llegados "por mi policía secreta" y exigiendo "fianza de buena conducta a los que no me agradan". Finalizaba su comunicación al encargado del poder ejecutivo informando sobre un denuncio realizado contra uno de los emigrados y sentenciando que de salir cierta su acusación lo ahorcaba "muy pronto", porque era "gente muy inmoral y corrompida", 21 .

Las medidas represivas de Montilla no lograban disipar los temores de las oligarquías nacionales y locales. En su natal Venezuela las conspiraciones de los pardos eran más continuas e incluso, según un contemporáneo, muy seguido se descubrían conspiraciones para comenzar una guerra de exterminio contra los blancos ${ }^{22}$. El mismo Montilla y algunos de los libertadores habían sido víctimas de la práctica de la igualdad de clases, a lo que se opusieron en el desarrollo de la primera república venezolana y por esa razón terminaron expulsados por la "pardocracia".

Coincidiendo con la crisis venezolana, el contemporáneo citado, señalaba cómo en la Provincia de Cartagena el conflicto con los pardos se repetía, pero promovidos por el senador Remigio Márquez, a quien se le pedía subir a la

20 Mariano Montilla al Excmo. Sr. General F. de P. Santander, etc. Santa Marta, febrero 28 de 1823 " Ibíd., № 2.744, pp. 180-181.

21 Mariano Montilla al Excmo. Sr. General F. de P Santander, etc. Cartagena, febrero 28 de 1823, Ibíd., $\mathrm{N}^{\circ} 2.711$, p. 113-114.

22 Véase, RESTREPO, José Manuel, Op. Cit., pp. 222,234,235,263, 308, 323 y 375. 
capital para que le rindiera cuentas a las autoridades de la Nación. El congresista cartagenero antes de acudir a la cita le escribió a Santander negando su relación con el "bajo pueblo" y, más grave aún, "Suponerme ideas de pardería, ni que yo pueda sentar principios tan detestables, es una herejía"23.

Pero mientras mulatos de piel clara como Márquez negaban relación alguna con los negros, mulatos o pardos cartageneros, todos ellos seguían expresándose en la República entera e integrándose a la nación colombiana, la que esperaban como resultado de la guerra de emancipación; pero, también, reclamando su igualdad como ciudadanos en cuanto al derecho de tener un empleo, a ser elegidos o a ejercer una profesión.

Además de esto, algunos tenían el poder de solicitar el nombramiento de sus amigos para altos cargos en los gobiernos locales y nacionales o de cuestionar lo realizado por el encargado del poder ejecutivo y lo manifestaban de manera categórica e imperativa: "Como V E. sin conocimiento de causa haya nombrado para Prefecto de este Departamento [del Magdalena] al señor doctor Esteban Díaz Granados, me tomo la libertad de manifestar a V E. que después de los grandes servicios del señor doctor Manuel Romay, a quien los pueblos nombraron de gobernador, y cuyo influjo ha contribuido mucho en la pronta rendición de la plaza, sería conveniente, a mi ver, a pesar que no es gustoso, que se le nombrase de primera autoridad del departamento o de la provincia. Granados, por otra parte no es de lo mejor para ese puesto, no por falta de inteligencia, sino por su excesiva bondad y comprometimientos" ${ }^{24}$.

\section{CONCLUSIÓN}

¿Existió realmente la nación colombiana entre 1810 y 1830 ? Evidentemente no. Ello supondría que se contaba con un modelo tipo de nación al que deberíamos remitirnos. Pero existió en cambio, un conjunto de

\footnotetext{
23 "Remigio Márquez al Señor Vicepresidente Francisco de Paula Santander, Boca de Sogamoso, agosto 20 de 1823”, en: CORTÁZAR, Roberto, Op. Cit., Tomo VII, N 2.374, pp. 225-226.

24 “Mauricio José Romero a Domingo Caicedo, Cartagena, mayo 31 de 1831", en: Archivo Epistolar del General Domingo Caicedo, Biblioteca de Historia Nacional, Bogotá, Editorial ABC, 1946, Tomo II, p. 290.
} 
representaciones colectivas que remitían a diferentes modelos de comunidad política. Ellas han sido formuladas como un tipo de representaciones colectivas de nación fundamentadas en la difusión de un pacto contractual consagrado en las constituciones políticas promulgadas durante ese período.

Ese tipo de representaciones colectivas tuvieron sus peculiaridades según la pertenencia racial a cada una de las clases sociales que integraban la estratificada sociedad cartagenera. En la construcción de esas representaciones cada clase social buscaba su reacomodo en la nueva situación política planteada por el cambio a un régimen republicano. A la vez, éste buscaba asimilar a todos los hombres de las clases sociales sin distinción de raza con la categoría ciudadano. Como ciudadanos todos estos hombres buscaron integrarse y reclamarse sujetos con derecho a gozar de la nación imaginada surgida de la guerra de emancipación.

El conjunto de esos elementos creó una situación hasta entonces inédita. Pero también, a partir de ese momento, los miedos y recelos comenzaron a invadir el proceso de construcción nacional colombiano. Un proceso en que los imaginarios fueron cambiando en función de los momentos, de las élites que los formulaban y de los elementos que los integraban: el temor a las castas, el fantasma del mulataje y la negritud, el miedo a los plebeyos (el pueblo), la defensa de la república y de la nación, el honor de servir a la patria. Pero también fue una situación que sirvió tanto para hacer sentir a los mulatos y negros integrados en la imaginada nación, como también para manejarlos y manipularlos políticamente por quienes procedían de esas clases sociales o estaban cerca de ellas. 